MATEC Web of Conferences 6, 01005 (2013)

DOI: $10.1051 /$ matecconf/20130601005

(C) Owned by the authors, published by EDP Sciences, 2013

\title{
Effects of polypropylene fibre type on occurrence of heat-induced concrete spalling
}

\author{
C. Maluk ${ }^{1}$, L. Bisby ${ }^{2}$ and G. Terrasi ${ }^{3}$ \\ ${ }^{1}$ PhD Candidate: School of Engineering, University of Edinburgh, UK \\ ${ }^{2}$ Arup Professor of Fire and Structures: School of Engineering, University of Edinburgh, UK \\ ${ }^{3}$ Head, Mechanical Systems Engineering, EMPA Dübendorf, Zurich, Switzerland
}

\begin{abstract}
This paper presents the results of an experimental study into the effects of including different types (cross section, diameter, length and supplier) and dosages of polypropylene (PP) fibres on the occurrence of heat-induced concrete spalling. A new fire testing methodology named the Heat-Transfer Rate Inducing System (H-TRIS) was developed and used in an attempt to tackle some of the shortcomings of standard furnace fire testing in the practical study of heat-induced concrete spalling.
\end{abstract}

\section{INTRODUCTION}

The building design industry has traditionally relied on the "inherent" fire safe characteristics of concrete in the fire-safe design of concrete structures. As rapid advances are made in the use of new construction techniques, innovative materials, and ground-breaking designs, as well as advances in concrete technology driven mainly by factors other than fire safety (i.e. sustainability, cost, ease of construction, etc.), the fire safety community has recognized inadequacies in using the century old furnace fire testing methodologies for studying and assuring regulatory compliance of modern, optimized reinforced concrete structures [1].

This paper presents results of a comprehensive yet practical experimental study of heat-induced concrete spalling, with emphasis on the use of polypropylene (PP) fibres to mitigate spalling. A novel fire testing methodology, named the Heat-Transfer Rate Inducing System (H-TRIS) [2], is described and used. A summary of test results on eleven different high-performance, high-strength, self-compacting concrete (HPSCC) mixtures is presented. The novel capabilities of the H-TRIS testing device allow parameters and conditions which promote (or avoid) the occurrence of spalling to be repeatable and inexpensively investigated.

\section{FIRE RESISTANCE TESTS ON CONCRETE - THE STATUS QUO}

The standard fire resistance test was essentially developed in the early 1900s in an effort to standardise a field in need of regulation and material/product/design comparison (i.e. a system for standardising fire performance ratings was needed). A fundamental problem with furnace tests is that the heat flux absorbed by the specific material(s) being tested is neither directly controlled nor quantified, but rather is dependant on the gas phase temperature as well on the characteristics of the furnace (dimensions, lining, fuel, burners) [3, 4]. Moreover, the thermal properties of the material being tested will significantly influence the absorbed heat flux into a test specimen when tested in a furnace. More than half a century of advances has been unsuccessful in addressing the inherent problems with the furnace test $[1,5,6]$. Even

This is an Open Access article distributed under the terms of the Creative Commons Attribution License 2.0, which permits unrestricted use, distribution, and reproduction in any medium, provided the original work is properly cited. 

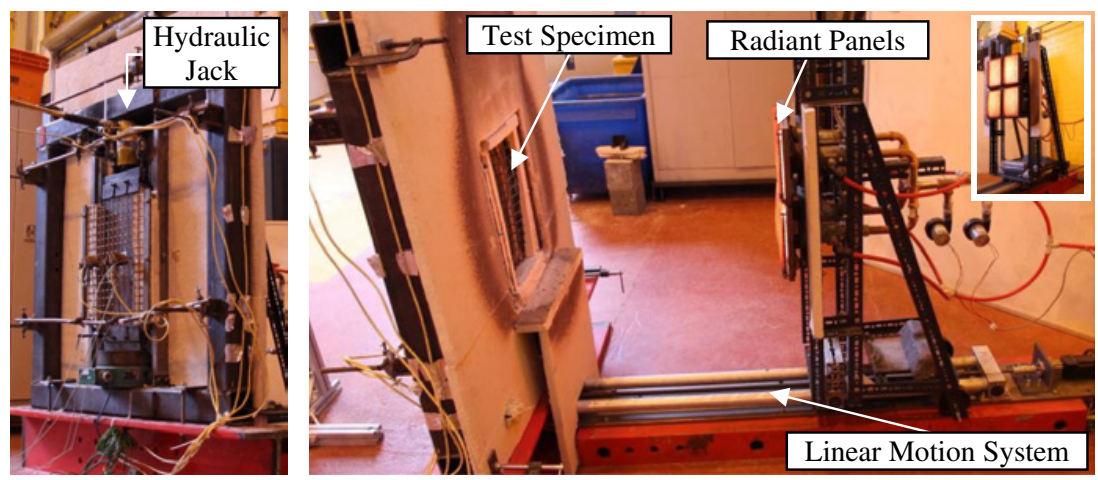

Figure 1. Multiple views of the Heat-Transfer Rate Inducing System (H-TRIS).

though furnace tests are controlled to follow a standard time-temperature curve [7,8], the equivalent thermal energy absorbed is never identical when testing materials with different thermal properties (e.g. concrete, timber, steel) or when testing in different specific furnaces. Moreover, the mechanical boundary conditions of test elements in standard fire resistance tests rarely simulate those encountered by a real structural element in a real fire. There is compelling evidence that the complexities of real fires are not captured by furnace tests [9].

Material properties (thermal and thermo-mechanical) as well as full structural behaviour in fire have historically been defined almost entirely based on standard fire resistance testing of isolated structural elements in furnaces. Even modern research [9-12] continues to use furnace testing as a means to understand structural response to fire, despite the relatively poor repeatability and quantification available from furnace testing. The high costs of large scale furnace testing are a limiting factor for progress in structural fire engineering; high costs restrict research programs to a very limited number of standard furnace tests, and hence very little statistical analysis of results is possible. Repeatability and the ability to accurately quantify the thermal loading to which materials and structural elements are exposed in a fire resistance test is a serious and legitimate concern $[13,14]$.

\subsection{Heat-induced concrete spalling}

The contemporary approach taken in practice to account (and mitigate) for the occurrence of heatinduced concrete spalling during fires is either to ignore it or to follow prescribed guidance. An example of prescribed guidance is given in Section 6.2 of EC 1992-1-2 [15], which lists the prescribed methods for to "avoid" spalling in concrete structures, while not actually requiring designers to demonstrate the potential for spalling in a given application. Indeed, by method D which suggests to, "include in the concrete mix more than $2 \mathrm{~kg} / \mathrm{m}^{3}$ of monofilament propylene fibres," [15] there is no explicit requirement to prove that $2 \mathrm{~kg} / \mathrm{m}^{3}$ is sufficient to prevent spalling, nor is there any statement to indicate what ranges of monofilament PP fibre geometry and composition will accomplish this.

\section{H-TRIS}

The H-TRIS test methodology developed for the current study uses a mobile array of propane-fired radiant panels with a mechanical linear motion system (Fig. 1). Whilst this is not the first time that mobile radiant panels have been used for thermal testing of construction materials [16, 17], to the authors' knowledge it is the first time that such an approach has been taken in an effort to understand and simulate the time-history of heat flux in a standard fire resistance test based on through thickness 
temperature measurements [2]. Thermal loading of test specimens is controlled using incident heat flux measurements taken by water cooled Schmidt-Boelter heat flux gauges during a pre-programmed calibration procedure. Calibration can be repeated before each new test to account for the specific ambient conditions on any given day, allowing a very high level of repeatability between tests. The computer-controlled linear motion system is used to adjust the radiant panels' location (i.e. distance from the specimen) so as to follow any pre-defined time history of incident or absorbed heat flux. H-TRIS thus allows accurate quantification of the energy absorbed by a tested element with good repeatability and at negligible economic and temporal costs compared to furnace tests [1]. It also allows rational simulation of any real fire or furnace exposure. A custom loading rig is used along with H-TRIS which is capable of inducing a compressive load on the test specimens of up to $400 \mathrm{kN}$ (axial or bi-axial and fixed or pinned boundary conditions).

\section{EXPERIMENTAL INVESTIGATION}

\subsection{Wider study on high-performance precast concrete elements}

The work reported herein is part of a larger study into the behaviour of thin-walled carbon fibre reinforced polymer (CFRP) pretensioned precast concrete slabs in fire. The combination of CFRP prestressing tendons and high performance self consolidating concrete (HPSCC) allows for highly optimized, light-weight prestressed elements, with reduced concrete cover and overall thickness while also providing excellent serviceability, fatigue, and durability performance. However, the fire behaviour of these novel elements is problematic on various grounds and needs to be better understood before they can be used with confidence.

During the initial stages of the wider study (during 2009-2010), a series of full-scale thin-walled CFRP HPSCC pretensioned slabs, produced by SACAC AG, Switzerland, were tested at EMPA, Switzerland in a standard fire resistance furnace [18]. The HPSCC mixture was designed to achieve a strength class $\mathrm{C} 90$. Materials such as this are becoming popular for producing slender precast prestressed elements. The HPSCC had a precise grain size distribution of $0-8 \mathrm{~mm}$ limestone aggregates, added silica fume, fly ash, and superplasticizers. The particular HPSCC mixture was designed to allow for optimum self-compacting conditions, with a slump flow of more than $750 \mathrm{~mm}$ at water-to-(cement + silica fume + fly ash) ratios in the range of $0.39-0.40$. Constructability required slump flows in this range and hence the use of large dosages of PP fibres was explicitly restricted. Guided by the recommendations given in the EC 1992-2-1 [15], PP fibres were used at a rate of $2 \mathrm{~kg} / \mathrm{m}^{3}$. With no particular type or geometry of PP fibres specified in the Eurocodes, the industry partner opted to use $20 \mathrm{~mm}$ long PP fibres with rectangular cross section $37 \times 200 \mu \mathrm{m}$. The melting temperature of the PP fibres was specified as $160^{\circ} \mathrm{C}$ to $170^{\circ} \mathrm{C}$. It is noteworthy that available guidelines state that "the melting point is an important characteristic where the fibre is to be used to modify the performance of concrete in fire" [19]; however no statement is made as to what melting temperature is desirable and why.

Six series of five loaded slabs were tested to the ISO 834 standard fire curve [7] in a floor furnace at EMPA. Slabs were simply supported with loading in four-point bending sufficient to reach decompression at the tension fibre in the central region. Slabs had a rectangular cross-section, 45, 60 or $75 \mathrm{~mm}$ thickness, and were $200 \mathrm{~mm}$ wide. All slabs were tested with an exposed length of $3040 \mathrm{~mm}$ and 130,160 or $280 \mathrm{~mm}$ of cold overhang at each end. The $5.4 \mathrm{~mm}$ diameter CFRP tendons were located at the mid-plane of the slabs in order to obtain a central prestress, and were stressed to either 800 or $1200 \mathrm{MPa}$. Full details of this prior work are given elsewhere [18]. From the analysis of the fire tests on 30 slabs it was concluded that: (1) the fire resistance of the slabs was mainly limited by heat-induced spalling of the HPSCC; and (2) spalling mainly occurred around the prestress transfer zone where the precompressive stress at the heated face was greatest. 
Table 1. Experimental Test Matrix.

\begin{tabular}{|c|c|c|c|c|c|c|c|}
\hline \multirow{2}{*}{$\begin{array}{l}\text { Mix } \\
\text { Label }\end{array}$} & \multicolumn{4}{|c|}{ PP fibre type } & \multicolumn{3}{|c|}{ Fibre Parameters } \\
\hline & Supplier & $\begin{array}{l}\text { Cross- } \\
\text { section }\end{array}$ & Length & $\begin{array}{c}\text { PP dosage } \\
{\left[\mathrm{kg} / \mathrm{m}^{3}\right]}\end{array}$ & $\begin{array}{c}\text { Total surface } \\
\text { area of PPs }\left[\mathrm{m}^{2}\right]\end{array}$ & $\begin{array}{l}\text { Total length } \\
\text { of PPs [km] }\end{array}$ & $\begin{array}{l}\text { Total \# of PPs } \\
\text { [mill. of PPs] }\end{array}$ \\
\hline 042 & \multicolumn{4}{|c|}{ None } & - & - & - \\
\hline 132 & \multirow{2}{*}{ Baekart } & $18 \mu \mathrm{m}$ & \multirow{2}{*}{$6 \mathrm{~mm}$} & 0.68 & 165 & 2915 & 486 \\
\hline 142 & & $32 \mu \mathrm{m}$ & & 1.20 & 165 & 1640 & 273 \\
\hline 341 & \multirow{5}{*}{ Propex } & \multirow{5}{*}{$32 \mu \mathrm{m}$} & \multirow{2}{*}{$3 \mathrm{~mm}$} & 1.20 & 165 & 1640 & 547 \\
\hline 342 & & & & 2.00 & 275 & 2733 & 911 \\
\hline 343 & & & \multirow{2}{*}{$6 \mathrm{~mm}$} & 1.40 & 192 & 1913 & 319 \\
\hline 345 & & & & 1.20 & 165 & 1640 & 273 \\
\hline 344 & & & $12 \mathrm{~mm}$ & 1.20 & 165 & 1640 & 137 \\
\hline 241 & \multirow{3}{*}{ Vulkan } & \multirow{3}{*}{$\begin{array}{c}37 * 200 \\
\mu \mathrm{m}\end{array}$} & \multirow{3}{*}{$20 \mathrm{~mm}$} & 1.20 & 84 & 178 & 15 \\
\hline 242 & & & & 2.00 & 141 & 297 & 25 \\
\hline 243 & & & & 2.34 & 165 & 348 & 29 \\
\hline
\end{tabular}

\subsection{Testing matrix}

The full-scale tests demonstrated that efforts were needed either to further understand, or better completely avoid, the occurrence of heat-induced spalling; however it was recognized that additional furnace testing was cost-prohibitive. Scaled specimens were therefore cast and tested for spalling using H-TRIS. The authors recognize that in structural fire resistance testing scaling is questionable on a variety of grounds [1]. Thus, in the direction of the principal heat flow the sample dimensions were not scaled, producing specimens with the same cross-section as the full-scale slabs but with a length of only $500 \mathrm{~mm}$. Cold overhangs of $50 \mathrm{~mm}$ were required at the ends of the specimens, resulting in a thermally exposed surface of $400 \times 200 \mathrm{~mm}^{2}$. The overall test matrix in the current study was defined with the primary objective of defining an HPSCC mixture that could be used to cast full-scale thin-walled CFRP HPSCC pretensioned slabs with a guarantee that no heat-induced concrete spalling would occur when tested in a standard furnace test.

Eleven candidate concrete mixtures were selected and tested either under sustained compressive stress with rotationally fixed boundary conditions, or under a free and unrestrained condition, in order to replicate the extremes of possible mechanical condition experienced during the furnace testing. The parameters assessed were strictly related to the type of PP fibre (cross section, diameter, length and supplier) and dose, with mild variations in the concrete mixture to attain the optimum self-compacting conditions required for constructability. A review of studies on heat-induced concrete spalling [20-22] informed the choices of parameters to be varied to assess the type of PP fibre and dosage.

The small scale testing matrix is shown in Table 1. For each of the eleven candidate mixes six specimens were cast by the industry partner in Switzerland; three of these were tested under sustained compressive stress and three were tested with zero global compressive stress. Specific PP fibre dosages were defined to assess the influence of three pre-defined comparative factors: total surface area of PP fibres (mixtures 132, 142, 341, 345, 344), total length (mixtures 142, 341, 345, 344), and total number. All tests were performed in triplicate. To replicate the mechanical conditions encountered in the region of the prestress transfer zone in the full scale slabs, which is where much of the spalling occurred in the standard furnace tests [18], axial compressive loading was applied on the specimens' central longitudinal axis to simulate the initial precompressive stress in concrete at the beginning of the tests; a stress of 12.3 MPa averaged over the cross-section.

H-TRIS was programmed to impose thermal loading on the scaled specimens, equivalent to the thermal loading experienced by the full scale slabs tested in the furnace tests at EMPA. Based on the premise that the evolution of temperature gradients through the specimens' depth is the critical parameter indicating a true equivalence of thermal insult on the test specimens, replicating the internal 
Table 2. Results of spalling tests in H-TRIS.

\begin{tabular}{|c|c|}
\hline $\begin{array}{c}\text { Mix } \\
\text { Label }\end{array}$ & $\begin{array}{c}\text { Sustained } \\
\text { compressive } \\
\text { stress }\end{array}$ \\
\hline \multirow{2}{*}{042} & $0 \mathrm{MPa}$ \\
\cline { 2 - 2 } & $12.34 \mathrm{MPa}$ \\
\hline \multirow{2}{*}{341} & $0 \mathrm{MPa}$ \\
\cline { 2 - 2 } & $12.34 \mathrm{MPa}$ \\
\hline \multirow{2}{*}{241} & $0 \mathrm{MPa}$ \\
\cline { 2 - 2 } & $12.34 \mathrm{MPa}$ \\
\cline { 2 - 2 } & $0 \mathrm{MPa}$ \\
\hline \multirow{2}{*}{242} & $12.34 \mathrm{MPa}$ \\
\hline
\end{tabular}

\begin{tabular}{|c|c|c|c|}
\hline \multirow{2}{*}{$\begin{array}{c}\text { Time to spall } \\
{[\mathrm{min}]}\end{array}$} & \multirow{2}{*}{$\begin{array}{c}\begin{array}{c}\text { Heat } \\
\text { Density } \\
\text { Absorbed }\end{array} \\
{\left[\mathrm{kJ} / \mathrm{cm}^{2}\right]}\end{array}$} & \multicolumn{2}{|c|}{ Mass spalled } \\
\hline & & {$[g]$} & {$[\%]$} \\
\hline 10.9 & 2.28 & 208 & $2.0 \%$ \\
\hline 24.7 & 5.99 & 664 & $6.3 \%$ \\
\hline 13.9 & 3.01 & 1135 & $10.7 \%$ \\
\hline 12.5 & 2.66 & 1281 & $12.1 \%$ \\
\hline 11.0 & 2.31 & 679 & $6.3 \%$ \\
\hline 13.1 & 2.81 & 1189 & $11.2 \%$ \\
\hline 17.1 & 3.85 & 923 & $8.4 \%$ \\
\hline 14.6 & 3.19 & 268 & $2.4 \%$ \\
\hline 16.5 & 3.67 & 435 & $4.0 \%$ \\
\hline 16.3 & 3.64 & 3095 & $28.5 \%$ \\
\hline 13.0 & 2.80 & 2043 & $18.7 \%$ \\
\hline 14.4 & 3.16 & 2645 & $24.4 \%$ \\
\hline 12.4 & 2.66 & 420 & $3.8 \%$ \\
\hline 7.9 & 1.61 & 100 & $0.9 \%$ \\
\hline 11.7 & 2.49 & 238 & $2.2 \%$ \\
\hline 7.3 & 1.48 & 251 & $2.3 \%$ \\
\hline 14.3 & 3.11 & 210 & $1.9 \%$ \\
\hline 12.5 & 2.66 & 784 & $7.2 \%$ \\
\hline- & - & - & - \\
\hline- & - & - & - \\
\hline- & - & - & - \\
\hline 9.9 & 2.07 & 438 & $4.1 \%$ \\
\hline 9.4 & 1.93 & 423 & $4.0 \%$ \\
\hline 10.6 & 2.22 & 1503 & $14.3 \%$ \\
\hline
\end{tabular}

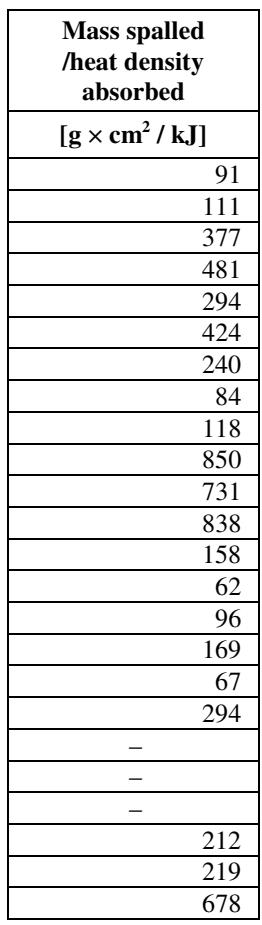

thermal gradient evolution was the crucial issue in the current study. Through-thickness temperature measurements at 10, 20 and $45 \mathrm{~mm}$ from the exposed surface, obtained during the furnace tests of the full scale specimens, were used as inputs for an inverse heat transfer model to calculate the necessary absorbed heat flux that generated the observed thermal gradients from the furnace tests following ISO 834 [2].

\section{RESULTS AND DISCUSSION}

All 66 small scale tests were performed during a period of only 30 days. The results are summarized in Table 2 and demonstrate clear differences in the time to spalling and amount of spalling when using different types of PP fibres at different dosages (in cases where spalling occurred). The moisture content of the test specimens at the time of testing was 4.0 to $5.0 \%$ (by mass); 13 to 16 months from casting. Cube compressive strengths at 6 months age ranged between 103 and $112 \mathrm{MPa}$.

\subsection{Validation of the thermal loading}

The comparison of through thickness temperature measurements between effectively identical concrete elements tested in the EMPA floor furnace (grey shaded bands) and in H-TRIS (black lines) is given in Figure 2, thus validating the use of this technique, particularly in replicating the thermal gradients imposed by a given furnace. Figure 2 also illustrates the excellent repeatability of H-TRIS tests as compared with the variability inherent in furnace tests.

\subsection{Assessment of spalling}

Propensity for concrete spalling has traditionally been assessed through furnace testing by visual evaluation of the concrete surface, and occasionally by measuring the depth, volume, or mass of spalled 


\section{MATEC Web of Conferences}

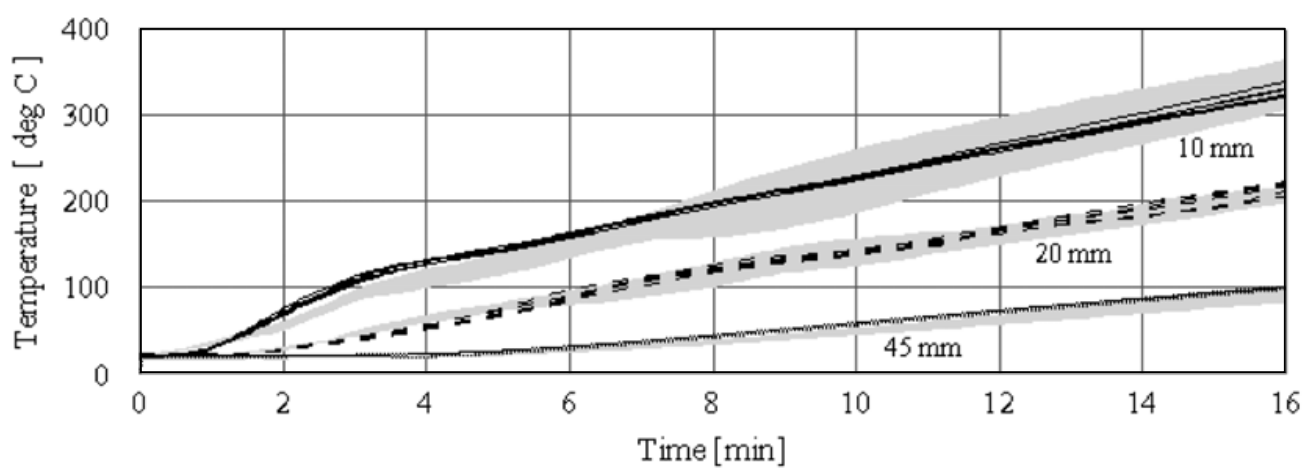

Figure 2. Internal temperatures recorded in furnace (ISO 834) compared to those from H-TRIS.

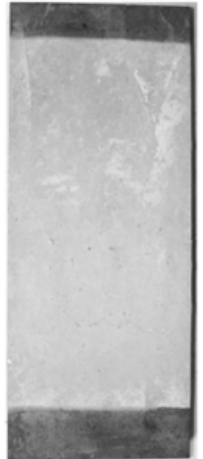

Mix 342

(no spalling)

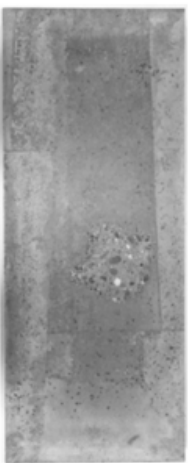

Mix 241

(100 g spalled)

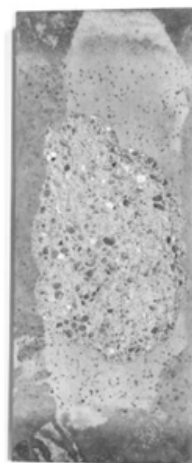

Mix 242 (1503 g spalled)

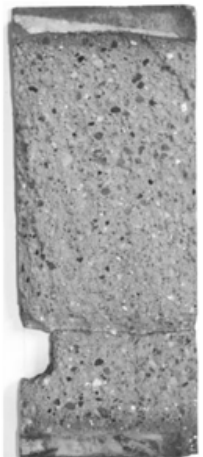

Mix 341

(3095 g spalled)

Figure 3. Post-test photographs of specimens tested with H-TRIS.

concrete from the specimen. The H-TRIS methodology makes it possible also to accurately quantify the time to first spalling, the mass spalled, and the total absorbed heat density up to the moment of first spalling; this is calculated as the area under the curve in the absorbed heat flux versus time curve divided by the concrete mass.

Since the objective of the current study to avoid heat-induced spalling completely, rather than to develop a deep understanding of the mechanisms involved, which the authors feel is an unrealistic and to some extend wrong-minded objective, tests were continued only until first spalling. If no spalling occurred within 60 minutes of heating the test was halted. Spalling of the specimens occurred for four of the candidate concrete mixtures (mixtures 042, 341, 241 and 242). For mixtures in which spalling occurred under sustained compressive stress, spalling also occurred under a free-to-expand condition, with the exception of mixture 242. A summary of the results for those mixtures that experienced spalling is given in Table 2. It should be noted that the initial mass was between 10.5 and $10.9 \mathrm{~kg}$. It is noteworthy that we do not differentiate between mass loss due to heat-induced spalling and mass loss due to moisture. Before and after photographs of some of the test specimens with different levels of spalling (i.e. mass spalled) are shown in Figure 3.

Heat-induced concrete spalling only occurred for mixtures 042, 341, 241 and 242, between 7 and 25 minutes from the start of the test. This is similar to the time to spalling in the full-scale standard fire resistance tests on HPSCC slabs. Spalling occurred for concrete mixtures with the relatively low levels of the fibre parameters (Table 1) (mixtures 042, 341, 241, and 242), indicating the relevancy of 


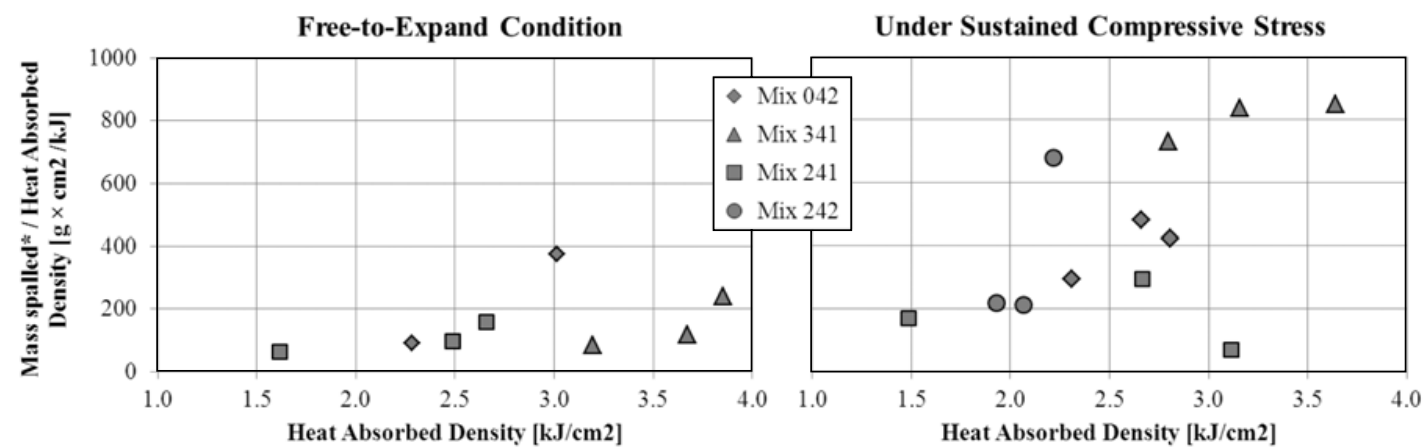

Figure 4. Mass spalled versus heat absorbed density.

evaluating such parameters. Long individual PP fibre length appears to have a beneficial effect on the occurrence of spalling, when comparing mixtures 341, 345 and 344. These mixtures had identical total surface area and total length of PP fibres, but for mixtures with longer individual PP fibre length, thus lower total number of PP fibres (refer to Table 1), spalling was avoided. This proved to be in accordance with the findings found by Smith and Atkinson [23]. These findings are not conclusive; mixtures 241 and 242 included $20 \mathrm{~mm}$ long PP fibres (see Table 1) but much lower fibre parameters, than all other mixtures, thus resulting in the occurrence of spalling when tested with the H-TRIS.

Figure 4 illustrates the correlation between the mass spalled and the absorbed heat density up to the moment of first spalling. The results indicate that when heat-induced spalling occurs at an early stage of the test, the mass spalled is considerably lower than when it occurs at a later stage. This is expected given that more accumulated thermal (and thermo-mechanical) energy will result in more energy being released when failure initiates; thus more concrete mass spalled. This was more obvious for specimens tested under sustained compressive stress, confirming that compressive stress exacerbates propensity for severe explosive spalling.

\section{CONCLUSIONS}

The parameters assessed in this study included the PP fibres' cross section, length, dosage and supplier, while evaluating the influence of the pre-defined fibre parameters: total surface area, total length and total number of PP fibres for different concrete mixtures. Test results showed that spalling occurred when at least one of these factors was relatively low, though none of them seems to be exclusively determinant in the effectiveness of PP fibres to avoid the occurrence spalling. The individual length of the PP fibres appears to be an important parameter in the occurrence of spalling; however, further testing is needed before conclusive statements can be made.

The capability of the H-TRIS to accurately quantify the thermal and mechanical conditions within a furnace test with precision and repeatability, and at negligible economical and temporal cost, has been shown. The versatility of the new testing methodology allowed simulation of the thermal and mechanical conditions of a standard fire resistance test in a floor furnace.

\section{References}

[1] Harmathy T.Z. and Lie T.T., Fire Test Standard in the Light of Fire Research, Fire Test Performance, ASTM STP 464, American Society for Testing and Materials, 85-97, 1970.

[2] Maluk C., Bisby L., Terrasi G., Krajcovic M., and Torero J.L., Novel Fire Testing Methodology: Why, How and What Now?, Proceedings of the $1^{\text {st }}$ International Conference on Performance Based and Life Cycle Structural Engineering (PLSE), 11pp, 2012. 


\section{MATEC Web of Conferences}

[3] Sultan M.A., Harmathy T.Z., and Mehaffey J.R., Heat transmission in fire test furnaces, Fire and Materials, 10(2), 47-55, 1986.

[4] Welch S. and Rubini P.A., Three-dimensional Simulation of A Fire-resistance Furnace, Proceedings of the $5^{\text {th }}$ International Symposium on Fire Safety Science, 1009-1020, 1997.

[5] Harmarthy T.Z., The fire resistance test and its relation to real-world fires, Fire and Materials, 5(3), 112-122, 1981.

[6] Wickström U., The plate thermometer - a simple instrument for reaching harmonized fire resistance tests, Fire Technology, 30(2), 195-208, 1994.

[7] ISO, ISO 834: Fire Resistance Tests - Elements of Building Construction. International Organization for Standardization, Geneva, Switzerland, 25pp, 1999.

[8] ASTM, Test Method E119-12: Standard methods of fire test of building construction and materials, American Society for Testing Materials, West Conshohocken, PA, 34pp, 2012.

[9] Bisby L., Gales J., and Maluk C., A contemporary review of large-scale nonstandard structural fire testing. Fire Science Reviews, 2013. (in press)

[10] Stadler M., Mensinger M., Schaumann P., and Sothmann J., Munich Fire Tests on Membrane Action of Composite Slabs in Fire - Test Results and Recent Findings, Proceedings of the International Conference on Applications of Structural Fire Engineering, Prague, Czech Republic, 177-182, 2011.

[11] Mostafaei H., RR-316 - Hybrid Fire Testing for Performance Evaluation of Structures in Fire Part 1: Methodology, National Research Council of Canada, Ottawa, 2011.

[12] Vassart O. and Zhao B., FRACOF Engineering Background. Report developed for the project Leonardo Da Vinci: Fire Resistance Assessment of Partially Protected Composite floors (FRACOF), 2011.

[13] Ödeen K., "Fire Test Standard in the Light of Fire Research", ASTM Special Technical Publication 464, 30-56, 1970.

[14] Law M., Designing fire safety for steel - recent work, Proceedings of the ASCE Spring Convention, American Society of Civil Engineers, New York, 11-15 May, 1981.

[15] Eurocode 2, EN 1992-1-2: Design of concrete structures - Part 1.2: General rules - Structural fire design, European Committee for Standarisation, Brussels, Belgium, 2004.

[16] Mowrer F.W., Window Breakage Induced by Exterior Fires, NIST-GCR-98-751, National Institute of Standards and Technology, Gaithersburg, MD, USA, 1998.

[17] Sakji S., Soize C., and Heck, J. Probabilistic Uncertainty Modeling for Thermomechanical Analysis of Plasterboard Submitted to Fire Load, Journal of Structural Engineering, 134(10), 1611-1618, 2008.

[18] Terrasi G.P., Bisby L., Barbezat M., Affolter C., and Hugi E., Fire Behavior of Thin CFRP Pretensioned High Strength Concrete Slabs, Journal of Composites for Construction, 16(4), 381-394, 2012.

[19] British Standard, BS EN 14889-2:2006, Fibres for concrete - Part 2: Polymer fibres - Definitions, specifications and conformity, 30pp, 2006.

[20] Khoury G., and Anderberg Y., Concrete Spalling Review, Report submitted to the Swedish National Road Administration, 60pp, 2000.

[21] Kodur V., Spalling in high strength concrete exposed to fire - Concerns, causes, critical parameters and cures, ASCE Structures Congress, Philadelphia, PA, 9pp, 2000.

[22] Hertz K. and Sørensen L., Test method for spalling of fire exposed concrete. Fire Safety Journal, 40(5), 466-476, 2005

[23] Smith K. and Atkinson T. Factors to consider in using PP fibres in concrete to provide explosive spalling resistance in the event of a fire. Shotcrete Elem. of a Syst., CRC Press, 261-268, 2010. 